\title{
The Role of MIS in Business Decision Supporting: Applications and Features
}

\author{
Dr. P. Devaraju, \\ Department Name, University/ Asst. \\ Professor, Dept. of Computer Science \\ \& Technology, Sri Krishnadevaraya \\ University, Anantapuramu
}

\begin{abstract}
The role of Management Information Systems is described and analyzed in light of its capability for decision making. Decision making process and its impact on top level management in a business organization is explained with an emphasis on automated decision making. Limitations and challenges of MIS are discussed and a set of six recommendations proposed for increasing the effectiveness of MIS in the decision making process.
\end{abstract}

\section{Keywords}

Information Systems, Transactional Processing Systems, TPS, Management Information Systems, MIS, Expert Systems

\section{INTRODUCTION}

Information Systems can be conceptualized in terms of three types of systems: Transactional Processing Systems (TPS), Management Information Systems (MIS), and Expert Systems. MIS has several subsets such as Decision Support Systems and Executive Information Systems. The role of MIS in decision support is best discussed in the context of the subset referred to as Decision Support System (DSS). A DSS is a computer based system (an application program) capable of analyzing an organizational (or business) data and then presents it in a way that helps the user to make business decisions more efficiently and effectively. It is basically an informational application which depends on the information already input while answering to a given query. For example, a decision support system could provide:

- Comparative sales figures for one week/month and the next

- Projected revenue figures based on new product sales assumptions

- Consequences of different decision alternatives, given past experience

Sometimes there is an overlap between the broad categories of IS and a DSS could be capable of presenting information graphically through an expert system or artificial intelligence (AI). Usually the DSS is used by all levels of people within a business organization. Top level management uses DSS for strategic decisions, middle management uses for tactical decision while first line supervisors use deploy it for day-to-day operational decisions.

Therefore, the process of decision-making in any business is an inherently vital aspect not just for organizations but also for individuals who greatly rely on these decisions for their survival in the highly competitive arena of entrepreneurship (Al-Zhrani, 2010, p.1249-1251). More importantly, Management Information System (commonly abbreviated as MIS) has been an increasingly used tool in the institutionalization and making of decisions. DSS are a subset of MIS, for intelligent decision making. However, despite the immense benefits that result from using MIS in decision making, some critics have, reportedly, been slowly-but surely-asserting that MIS poses surmountable detrimental effects to organizations and should thus be used sparingly or avoided if possible (Demetrius, 1996). According to Kumar (2006), in order to define MIS, it must be principally divided into the three facets that constitute it - which are: management, information, and systems. In furthering his ideas, Kumar simply defines management as the process through which managers plan, organize, initiate and control operations within their businesses. Essentially, a management can only exist when there are subjects/ workers to be managed (Al-Zhrani, 2010, p.1248-1252; The Maniac, n.d.).

Kumar also states that information generally refers to analyzed data. In other words, information (with regards to business) results from data that is analyzed using business statutes, principles and theories advanced by various macroeconomists. Finally, system, according to Kumar, refers to "A set of elements joined together for a common objective." More often than not, business systems normally consist of smaller systems - known as subsystems - which all function towards ensuring efficacy of the large systems. As a matter of fact, systems vary from one organization to another depending on the nature of organizational operations, size of the businesses and organizational priorities among many other salient factors. Based on the foregoing definitions, Management Information Systems refers to a system that uses information in order to ensure apt management of businesses. Fundamentally, all the facets of MIS run concomitantly in order to ensure overall efficiency of the whole system. Failure in one part means overall failure for the other parts since they are all designed to function interdependently (Davenport \& Short, 1990). Consequentially, a good management of information systems leads to good decision-making in business just in the same way poor management leads to poor decision making. It is based on this foundational concept that this paper is going to circumspectly analyze the roles of management systems in decision making. Notably, this study will be arranged as follows. The study will begin by giving a brief overview into the decision making process in businesses while establishing the point 
in which it links with MIS. From here, an expansive analysis and review will be done on the roles of MIS in improving decision making. This will then be followed by a mentioning of the questionable areas associated with MIS and decision making. After that, recommendations will be given to solve the underlying issues that result from the paper. Finally, a conclusion will be given to summarize the contents of the paper.

\section{Main Discussion-Role of MIS in Improving decision making}

Preliminarily, it is inherent to state that decision making is an integral part of any business (The maniac, n.d.). This is because a majority of operations in an organization revolve around decisions made by the management and other key stakeholders in the organization. And in order for decision to be made adequately, it is vital for there to be a good information system since decisions are based on information available. In relations to this, Jahangir (2005) states that based on the significant role that information plays in choice of decision to be made, organizations must ensure that they have a good management information system. As a notable general observation, a good MIS ensures good decision making just in the same way bad MIS propel the making of bad decisions.UStudy.in (2010) supports the above observation by saying that "The quality of managerial decision-making depends directly on the quality of available information" and the managers should therefore cultivate an environment that encourages the growth and viable sprouting of quality information.

Essentially, before deciding on which MIS strategy to use, it is vital to ensure that the choice made is fully compatible with your current system. This will not only help in avoiding erratic choices but it will also save you the time and money that would have been otherwise wasted by that person (Rhodes, 2010; Jahangir, 2005). In addition to that, it is noteworthy for the MIS strategy or tool used to be in line with the decisions that are to be made. In other words, there should be a connecting point between the decision to be made and the MIS to be used by individual or corporate business owners (Jarboe, 2005). As a key consideration, Management Information Systems is a highly complex and delicate arena that calls for a lot of caution to be taken by its managers. It is for this reason that it is recommendable for organizations to ensure that they carefully select the individuals who are placed to control the systems. The more cautious and professional a person is, the better the person gets an assurance of positive prospects of in MIS with regards to decision making and other related areas of business (Lingham, 2006).

Having clearly delineated that, what then are some of the scholarly arguments, facts, opinions and observations made by various macroeconomists with regards to the roles of Management Information System in improving decision making? To begin with, MIS provides a fitting platform for good decision making (Kumar, 2006). Essentially, without the established systems of getting information in MIS, it would be extremely difficult for organizations to make their decisions. This is because they would be forced to making baseless information due to the lack of confirmed information. Moreover, MIS normally lays a firm foundation for the establishment of concrete decisions through its systematic tools, timely information and adequate managerial policies and regulations. Furthermore, Management information Systems' statutes regarding businesses act as guidelines to business owners when making critical decisions about their businesses. As a result, managers and key decision makers are bridled from overstepping their boundaries or exceeding

their business mandate. This is very crucial as it helps in keeping businesses checked and balanced thus ensuring that only proven decisions are considered while the untried ones are

thwarted. More importantly, the capacity to guide decisionmaking facilitates progress and improvement of the operations in a company (Lingham, 2006; Chambers, 1964, p.15-20). In addition, most MIS programs are endowed with the capacity to give real-time updates of the occurrences in company or system. By real-time, scholars simply refer to immediate updates of occurrences in a system. These immediate updates help mangers to take necessary actions as soon as is deemed appropriateespecially during the discovery and management of crises. This augments progress and improvement in company operations through timely decision-making.

This is important for companies in the modern-day generation where any slight lapse in decision making can lead to very huge losses (Allen, et al., 2010) Still, Management information systems are very elemental improving company securities (Davenport \& Short, 1990). For example, in many instances, most management information systems can be easily programmed by the owner to conduct certain actions at certain times. In effect, managers can program the system to perform certain routine checks which can help in improving efficiency of a company through easy discovery of bugs or problems. Furthermore, the programmability of most MIS saves a lot of priceless time and resources for owners. In other words, through programmability, business managers can program the systems to automatically discover certain deficiencies and even solve them. Consequently, the manager or system operator can use the time and resources he/she would have used in monitoring or fixing problems for other key uses. By routinely programming a Management Information System, the business is bound to make positive progress since time and resources can be easily channeled into rightful business paths (Allen, et al., 2010) As a fundamental point, a good number of MIS used today can perform multiple tasks all at the same time. This potential to multitask increases efficiency in a company since several business operations can be conducted simultaneously. With special regards to decision making, the capacity to multitask ensures that decisions are made speedily when compared to those systems which can only handle one task at a time. Closely related to the above point, Jahangir (2005) says that some MIS allow multiple users to access the same content all at the same time without any discrepancies. This potentiality boosts accountability from the business operators since multiple people can access a particular content and verify whether they are consistent or whether they are not. As a matter of fact, most organizations tend to suffer due to poor accountability from those charged with the mandate to manage certain details. This safeguard action of some MIS is what macroeconomists refer to as the "gate-keeping" role of MIS in decision making and overall well-being of the organization. On another level, a good number of MIS play the role of record keeping or institutionalization of data bases that can easily keep confidential or invaluable information. In essence, decision making often calls for the reading of certain past work (Jahangir, 2005). This is where record-keeping comes in handy. On the flipside, databases normally function towards providing future places of information retrieval. Principally, the record keeping and data-basing tool of MIS definitely ensures that decisions are made viably while 
businesses run smoothly. In contributing to the arguments regarding role of MIS in improving decision making,

\section{Rhodes (2010) also adds that:}

Management information systems give managers quick access to information. This can include interaction with other decision support systems, information inquiries, cross referencing of external information and potential data mining techniques. These systems can also compare strategic goals with practical decisions, giving managers a sense of how their decisions fit organizational strategy.

In summary, Rhodes simply believes that management information systems are a huge contributing factor in the getting of viable information from organizations. Sadly, very few organizations have been able to ardently take up on this role and even lead other organization in the society in doing the same. It is for this reason that there has been a limited improvement in decision making based on the tailoring of viable information. A candid way of solving this challenge is given later in this paper under recommendations.

Over the recent years, there has also been an increased usage of automated Management Information Systems. To a large extent, these automated systems have hugely revolutionized the decision-making process in a positive way (UStudy, 2010). For instance, by using automated MIS, companies no longer have to rely on 24-hour services from workers. Instead, the machines are able to be programmed to do things on our behalf (Jarboe, 2005). Of course this offers a huge plus in decision-making since managers are relieved of making some decisions-especially the technical ones which can be best interpreted and solved by the automated system.

As a cautionary point, organizations should not entirely rely on automated systems-- especially when the decisions to be made have adverse implications to the organization. This is based on the alleged observation that auto systems may sometimes be faulty and thus require frequent periodic monitoring (Demetrius, 1996). So in order not to fall a victim of over-relying on automated systems, Jahangir (2005) advices managers and company owners to ensure that they find a balance in utilizing the human element in operating while assigning some duties to the automate system. By blending the duties of these two extremes, Jahangir states that, this will ensure that both ends of the organization continue to actualize together while maximizing the potential for each side through check and balances of operations done by the management..Again, MIS is renowned for vesting its operations on systematic methods of operations. Crucially, this ensures that decisions made in a business are orderly and well-planned which, in effect, encourages objectivity during decision making. As a result, businesses and the decision-making process are improved through its systematic and orderly formula of operating (Jawadekar, 2006, p.363-370).

Jahangir (2005) adds that the principles, strategies and modes of operation in MIS can be intellectually used by macroeconomists to sieve between good and bad decisions. Once the sieving is done, good decisions are encouraged while the bad ones are sidelined and greatly discouraged. Effectually, this ensures positivity in terms of decisions made by organizationswhich, essentially, links up directly to improving the decision making process. A good number of scholars amass that MIS tends to be a more practical business tool with testable methods of operations. Its proposition and argumentations, therefore, provide tangible information that can be used to make substantiated decisions (Jawadekar, 2006, p.350- 355). This is in great contrast with a majority of business tools, existing today, which are mostly hypothetical. In effect, decisions founded on MIS tend to be accurate and viable when compared to its counterparts - which, in turn, encourage improvement of business decisions.

Finally, Management Information systems play the crucial role of providing a wide range of streamlined options from which decision-makers are able to make their preferred choices Vittal \& Shivraj (2008, p.359-361). Vitally, this ensures that whatever choices are made by decision makers, the outcome, more often than not, becomes positive. This, as a matter of fact, is the reason why many decision makers tend to prefer using MIS tools when making tough business choices. And as renowned concept, having good decision choices guarantees viable decisions in our businesses (Vittal \& Shivraj, 2008, p.360-365; Jawadekar, 2006, p.356-359).

\section{Conclusion and Recommendations}

Despite the positives associated with the role of MIS in decision making process, there are a few challenges that are believed to limit the efficacy of MIS. These include:

- The dynamic nature of MIS makes it difficult for some organizations to keep up with the principles, strategies, propositions or even ideas.

- Different situations call for different decisions to be made. This poses challenges to MIS theorists since some MIS tend to not be adaptable

- The institutionalization, programming, monitoring and evaluating MIS requires a lot of expertise-something which numerous organizations lack.

- The running of MIS programs tends to be relatively costly for some organization - especially small ones who are not wellendowed financially.

- MIS is more of a science-oriented field while business is art-oriented. Consequently, finding a middle ground where the two can be linked is quite challenging to some people.

- Most organizations do not a well-defined decision making system. So even with the right MIS tools, very little can be achieved in terms of improving decision-making. Based on these limitations - plus other underlying issues that arise from the main discussion, the following recommendations are suggested:

- There should be an increased monitoring of MIS so as to avoid falling victims of unobserved MIS which has dire ramifications.

- Managers and business owners should find a way of tailoring information in a way that it fits various decision making processes in variant businesses.

- The management should encourage the effectuation of a mutually interdependent and balanced MIS where workers and automated systems are handled with due respect. 


\section{The Role of MIS in Business Decision Supporting: Applications and Features}

- Business entities should find a way inculcating teachings about new MIS in order to reduce the trend of businesses being left behind on new inceptions.

- A well-defined decision making system should be fledged in businesses so as to provide a viable working environment for MIS. A good place to start here would be the inception of a centralized place where all decisions in businesses are channeled through - Business managers must ensure that they employ (or alternatively outsource) professional personnel who are able to ardently run both MIS and the decision making process.

Principally, it is inherent to note that in spite of the fact that this paper is expressively analytical, more research needs to be done in order to bring more information into public knowhow. Moreover, business owners must learn to cope up with the ever changing trends in MIS and decision making, without which it will be very challenging to make positive progress in decision making. Finally, it is vital to remember that improvement in decision making is fundamentally meant to ensure customer satisfaction while businesses continue to flourish in success. All MIS strategies should therefore be tailored in a way that the above business goals are achieved.

\section{REFERENCES}

[1] Allen, B., Heurtebise, A., \& Turnbull, J. (2010). Improving Information Access. Business Management US. Retrieved $\begin{array}{llll}\text { October } & 2, & 2010 & \text { from }\end{array}$ http://www.busmanagement.com/article/Improvinginformation-access/

[2] Al-Zhrani, S. (2010). Management information systems role in decision-making during crises: case study. Journal of Computer Science, 6(11), 1247-1251.

[3] Chambers, R. J. (1964). The role of information systems in decision making. Management Technology, 4 (1), 15-25.

[4] Davenport, T. H., \& Short, J. E. (1990). The new industrial engineering: Information technology and business process redesign. MIT Sloan Management Review. Retrieved October 2, 2010 from http://sloanreview.mit.edu/themagazine/articles/1990/summer/3141/the-newindustrialengineering-information-technology-and-business-processredesign/2/

[5] Demetrius, K. (1996). The role of expert systems in improving the management of processes in total quality management organizations. SAM Advanced management Journal. Retrieved October 2, 2010 from http://www.allbusiness.com/management/591381-1.html

[6] 6. Jahangir, K. (2005). Improving organizational best practice with information systems. Knowledge Management Review. Retrieved October 2, 2010 from http://findarticles.com/p/articles/mi_qa5362/is_200501/ai_n2 $1371132 /$

[7] Jarboe, K. P. (2005). Reporting intangibles: A hard look at improving business information in the U.S. Athena Alliance. Retrieved October 2, 2010 from http://www.athenaalliance.org/apapers/ReportingIntangibles. htm

[8] Kumar, P. K. (2006). Information System-Decision Making. Indian MBA. Retrieved October 2, 2010 from http://www.indianmba.com/Faculty_Column/FC307/fc307.ht $\mathrm{ml}$
[9] Jawadekar. (2006). Management information systems: Texts and cases. New York, NY: McGraw Hill.

[10] Kirk, J. (1999). Information in organizations: directions for information management. Information Research, 4 (3). Retrieved October 2, 2010 from http://informationr.net/ir/43/paper57.html

[11] Lingham, L. (2006). Managing a business/ Management information system. All Experts. Retrieved October 2, 2010 from http://en.allexperts.com/q/Managing-Business1088/management-information-system.htm

[12] Rhodes, J. (2010). The Role of Management Information Systems in Decision Making. eHow. Retrieved October 2, 2010 from http://www.ehow.com/facts_7147006_roleinformationsystems- decision-making.html

[13] The Maniac. (n.d.). Management information system: The center of management decision making. Helium. Retrieved October 2, 2010 from http://www.helium.com/items/242575management-information-system-the-center-of-managementdecision-making 